\title{
Aging Treatment Characteristics of Shear Strength in Micro Solder Bump
}

\author{
Chong-Hee $\mathrm{Yu}^{1}$, Kyung-Seob Kim²${ }^{2}$, Yong-Bin $\mathrm{Sun}^{3}$, Nam-Kyu Kim${ }^{4}$, , Nam-Hoon Kim ${ }^{4, *}$, \\ Heang-Suk $\mathrm{Oh}^{1}$ and Eui-Goo Chang ${ }^{4}$
}

${ }^{1}$ Electronics and Telecommunications Research Institute, Daejeon 205-350, Korea

${ }^{2}$ Department of Electronic Engineering, Yeojoo Institute of Technology, Yeojoo 469-800, Korea

${ }^{3}$ Graduate School of Industrial Technology, Kyonggi University, Suwon 442-760, Korea

${ }^{4}$ School of Electrical and Electronics Engineering, Chung-Ang University, Seoul 156-756, Korea

\begin{abstract}
The shear strength of the $\mathrm{Cr} / \mathrm{Cr}-\mathrm{Cu} / \mathrm{Cu} \mathrm{UBM}$ structure in both the high-melting solder bump and low-melting solder bump after aging were evaluated. SEM and TEM were examined in the intermetallic compounds and bump joint profiles at the interface between solder and UBM. The shear load concentrated on the bump was analyzed by finite element method. In 900-hour aging experiments, the maximum shear strength of $\mathrm{Sn}-97$ mass $\% \mathrm{~Pb}$ and $\mathrm{Sn}-37$ mass $\% \mathrm{~Pb}$ decreased by $25 \%$ and $20 \%$, respectively. The growth of $\mathrm{Cu}_{6} \mathrm{Sn}_{5}$ and $\mathrm{Cu}_{3} \mathrm{Sn}$ was ascertained by the aging treatment. The crack path changes from the interior of a solder to the intermetallic compound interface was evaluated. Compared with the $\mathrm{Cu}-\mathrm{Sn}$ IMC, the amount of Ni-Sn IMC was small. The Ni layer is considered as the diffusion barrier.
\end{abstract}

(Received June 24, 2002; Accepted October 21, 2002)

Keywords: solder bump, shear strength, aging, intermetallic compound, transmission electron microscopy

\section{Introduction}

As array area components have become smaller, the electronics industry has required smaller, lighter electronic components with higher working speed, to use in improving electrical performance of communication systems. Recently, there has been a great demand for development of semiconductor package technologies, such as chip scale package (CSP), multi chip package (MCP), flip chip package (FCP), and so on. ${ }^{1)}$ Among the package technologies, the flip chip technology, which uses the micro solder, directly attaches chips to land pads, which are used in semiconductors that require speed greater than $300 \mathrm{MHz}$. As the package become smaller, it is necessary to investigate the reliability of the fine joint area. ${ }^{2,3)}$ The intermetallic compound (IMC), grows at the solder and at the under bump metallurgy (UBM) interface at the practical operating temperature during the reflow process and eventually forms the solder bump. The IMC at the interface of the solder and the UBM causes cracks at the solder joint area owing to brittleness, and weakens the overall joint strength. ${ }^{4-8)}$

In this paper, the $110 \mu \mathrm{m}$ diameter solder bump was formed on the surface of a 32M SRAM die pad, and the mechanical joint strength between the solder and UBM before and after isothermal aging treatment was measured in the shear experiment. The growth behavior of IMC was also evaluated. Finally, the shear strength according to aging treatment in micro solder bump required for flip chip technology was investigated.

\section{Experimental Details}

The chip dimension was $8.0 \mathrm{~mm} \times 15.0 \mathrm{~mm} \times 500 \mu \mathrm{m}$, and 130 bumps were mounted on the chip surface by electroplating. The bump size was $110 \mu \mathrm{m}$ in diameter and $150 \mu \mathrm{m}$ in pitch. The height of the bump was $100 \pm 18 \mu \mathrm{m}$. The UBM

*Graduate Student, Chung-Ang University. structure was $\mathrm{Cr}(5000 \mathrm{~nm}) / \mathrm{Cr}-\mathrm{Cu}(15000 \mathrm{~nm}) / \mathrm{Cu}(60000 \mathrm{~nm})$. The pad open sizes are $50 \mu \mathrm{m}$ for the passivation layer and $70 \mu \mathrm{m}$ for the polyimide layer, respectively. In particular, when the high-melting $\mathrm{Sn}-97$ mass $\% \mathrm{~Pb}$ solder was used, a thick $\mathrm{Cu}$ layer was used to prevent complete consumption of the $\mathrm{Cu}$. The overall reflow time was five minutes, and the velocity of the conveyer was $0.55 \mathrm{~m} / \mathrm{min}$. The peak reflow temperature of $\mathrm{Sn}-97$ mass $\% \mathrm{~Pb}$ and $\mathrm{Sn}-37$ mass $\% \mathrm{~Pb}$ were $593 \pm 278 \mathrm{~K}$ and $503 \pm 278 \mathrm{~K}$ for 5 seconds, respectively. The time for liquid state was 60 seconds. WS613 water-soluble flux was used to remove the oxides and to form a uniform bump. The reflow temperature was controlled to restrain the IMC reaction by maintaining uniform melting of the solder bump, and to shorten the time of reaction with the UBM.

After the samples underwent aging treatment that enables the IMC to grow quickly, shear strength was measured. The samples were aged at the isothermal treatment of $448 \mathrm{~K}$ for 0, 300, 600, 900 hours. The bonding test machine (PTR1000) measured the shear strength. The tip of the machine moved at $0.2 \mathrm{~mm} / \mathrm{s}$. The distance between the chip and the tip was $2 \mu \mathrm{m}$. The shear strengths of two samples were measured each at 40 bumps. And the average value was calculated, discarding the maximum and the minimum values.

Scanning electron microscopy (SEM) connected to an energy dispersive spectroscopy (EDS) was used to examine the IMC layer on the surface of the ground sample. Highresolution transmission electron microscopy (HRTEM, JEM2010) was used to observe the microscopic structure. Using the focused ion beam (FIB) that has $\mathrm{Ga}^{+}$ion source at acceleration voltage of $50 \mathrm{kV}$, TEM sample was prepared. Finally, electron-transparent sample was made by micro milling with a $100 \mathrm{pA}$ ion beam. TEM with acceleration voltage of $200 \mathrm{kV}$ was used. Compared with other constituent layers of the package, the smaller UBM layer was analyzed by finite element analysis (FEA). Considering the length to width ratio for analysis, the model was simplified to contain the UBM, the solder bump, the aluminum pad, the passivation and the 
polyimide layer. Analysis model is composed of 1495 nodes and 458 elements. The displacement in the lower part of the pad was constrained in $x$-direction, and the origin in the coordinate axis was constrained in both $x$ - and $y$-direction. In the shear strength test, a $50000 \mathrm{mN}$ load was applied to a point on the solder bump in contact with the tip.

\section{Results and Discussion}

Figure 1 shows the shear strengths of $\mathrm{Sn}-97$ mass $\% \mathrm{~Pb}$ and $\mathrm{Sn}-37$ mass $\% \mathrm{~Pb}$ solders at various aging times at $448 \mathrm{~K}$. The results show that the shear strength tends to decrease

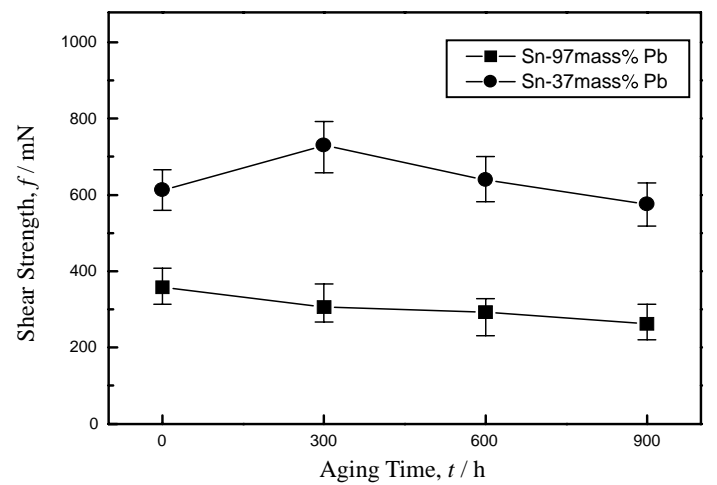

Fig. 1 Relation between aging time and shear strength at aging temperature $448 \mathrm{~K}$.
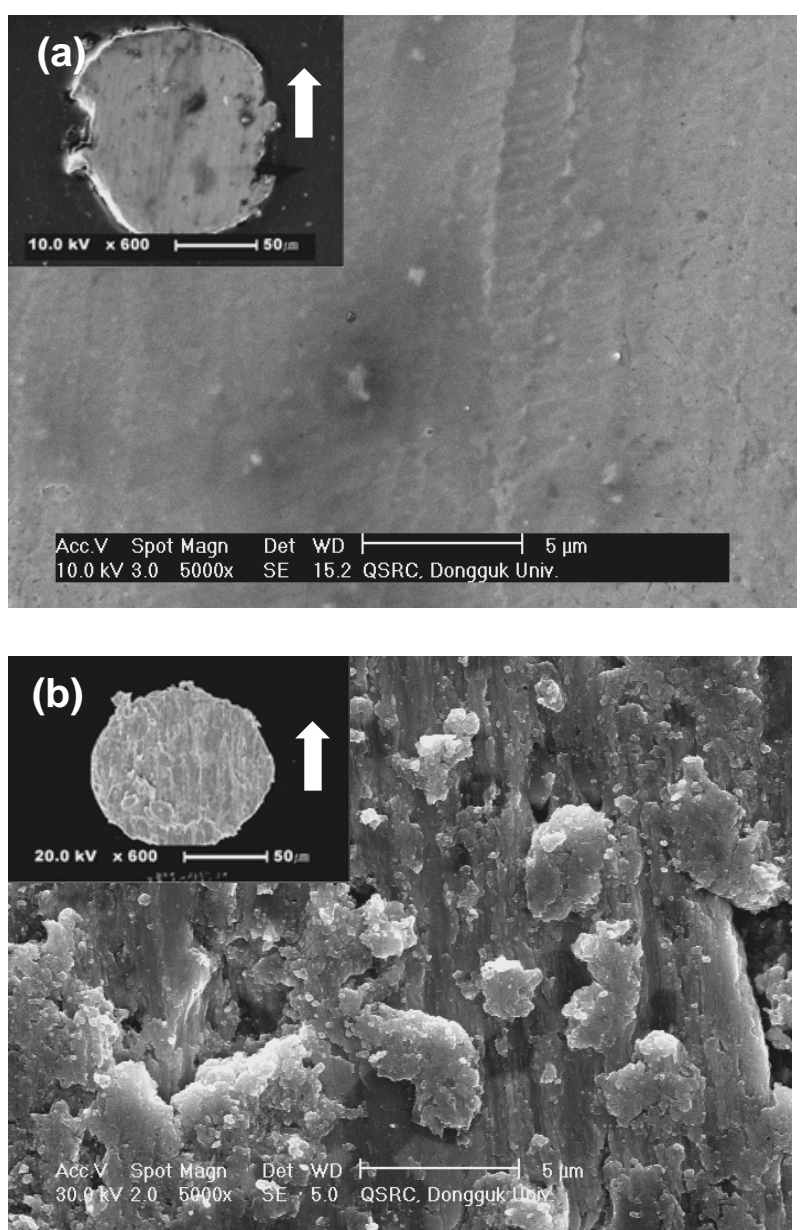

Fig. 2 Fractured surface of a sheared solder bump before aging treatment; (a) $\mathrm{Sn}-97$ mass $\% \mathrm{~Pb}$ (b) $\mathrm{Sn}-37$ mass $\% \mathrm{~Pb}$. with aging time. The average initial shear strength of $\mathrm{Sn}-$ 97 mass $\% \mathrm{~Pb}$ was $353 \mathrm{mN}$, but its shear strength after 900 hours of aging was $265 \mathrm{mN}$, a decrease of about $25 \%$ from the maximum value. The initial shear strength of $\mathrm{Sn}-$ 37 mass $\% \mathrm{~Pb}$ was $617 \mathrm{mN}$. Its shear strength, after 300 hours of aging, tended to increase to $725 \mathrm{mN}$, but decreased to $578 \mathrm{mN}$ after 900 hours of aging, a decrease of about $20 \%$ from maximum value. The small shear strength of $\mathrm{Sn}-$ 97 mass \% Pb may be due to the low mechanical strength of solder itself. On the other hand, the increase of the shear strength of the $\mathrm{Sn}-37$ mass $\% \mathrm{~Pb}$ sample after 300 hours of aging may be attributed to the increase in the thickness of IMC layer. Exceeding this critical point the shear strength of the sample decreased. The thickness of IMC layer did not exceed the critical thickness value up to the aging for 300 hours, and the critical thickness value in that is $3.3 \mu \mathrm{m}$.

Figure 2 shows the shear-fractured surfaces of the two different solders before aging. They indicate the ductile fracture associated with $\mathrm{Pb}$ in the solder. The white arrows in Fig. 2 and Fig. 3 represent the direction of the tester tip in the shear test.

Figure 3 shows the shear-fractured surfaces after the aging for 900 hours. In Fig. 3(a), the shape of an inverted triangle, which means that the lower part (meaning the initial contact area of the shear test) is narrow but the higher part (the end contact area) is wide because the ductile deformation mode
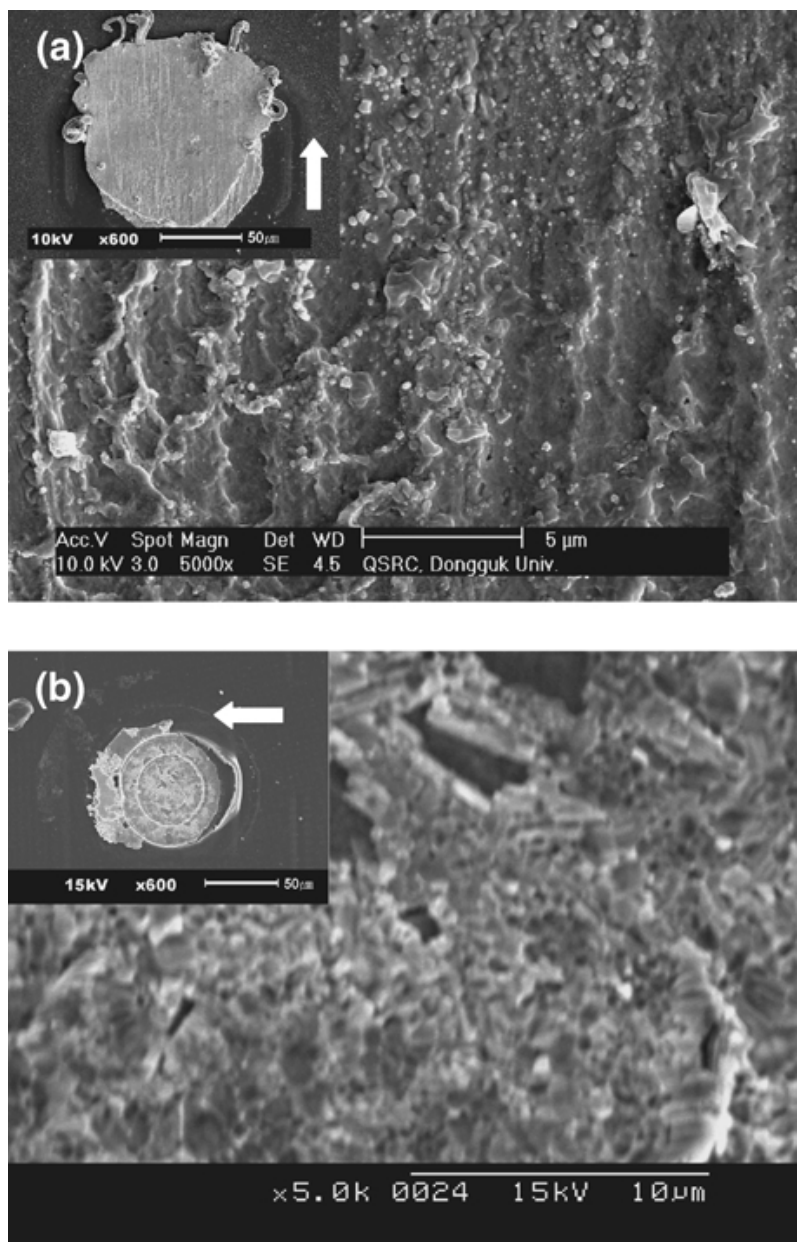

Fig. 3 Fractured surface of a sheared solder bump after aging at $448 \mathrm{~K}$ for 900 h; (a) Sn-97 mass\%Pb (b) Sn-37 mass\%Pb. 
of the large content of $\mathrm{Pb}$ stands out. On the other hand, Fig. 3(b) shows that the fractured surface remained relatively circular corresponding to the contact forms of the UBM and the solder. Figure 4 shows the result of EDS analysis of the Sn97 mass $\%$ Pb sample after it was aged for 900 hours. The $\mathrm{Cu}$ elements detected at the fractured surface of the sample after aging indicated the exposure of IMC formed between $\mathrm{Cu}$ and Sn.

There were no detected $\mathrm{Cu}$ elements up to 600 hours of aging. This means that shear failure occurred inside of the solder not at the UBM multi-layer, which, in turn, suggests that the joint connecting the solder and the UBM was firm. However, the path of fracture gradually moved from inside of the solder to interface of the IMC layer as $\mathrm{Cu}$ elements increased to 0.78 mass \% after the aging for 900 hours. Consequently, the IMC growth and grain coarsening decrease the shear strength.

Figure 5 shows the IMC layer at the cross-sectional surfaces of two different samples that were aged for 900 hours. The IMC layer clearly appeared in the sample of Sn37 mass $\% \mathrm{~Pb} . \mathrm{Cu}_{6} \mathrm{Sn}_{5}$ was detected initially at the joint before the aging, while $\mathrm{Cu}_{3} \mathrm{Sn}$ as well as $\mathrm{Cu}_{6} \mathrm{Sn}_{5}$ was detected after the aging. $\mathrm{Cu}_{6} \mathrm{Sn}_{5}$ formed in the solder side between the solder and $\mathrm{Cu}$. It is produced due to the high solubility of $\mathrm{Cu}$ (about 2 at $\%$ ) and the high diffusion coefficient of $\mathrm{Cu}$ $\left(1.8 \times 10^{-4} \mathrm{~cm}^{2} / \mathrm{s}\right)$ in the liquid phase solder. $\mathrm{Cu}_{3} \mathrm{Sn}$ was not detected in the initial joint because the nucleus of $\mathrm{Cu}_{3} \mathrm{Sn}$ is more difficult to generated than that of $\mathrm{Cu}_{6} \mathrm{Sn}_{5} \cdot{ }^{4} \mathrm{Cu}_{3} \mathrm{Sn} \mathrm{IMC}$ grows as $\mathrm{Cu}_{6} \mathrm{Sn}_{5}$ is consumed when $\mathrm{Cu}$ diffuses to the solder. Figure 5(a) shows the formation of the $1.4 \mu \mathrm{m}$ thick IMC
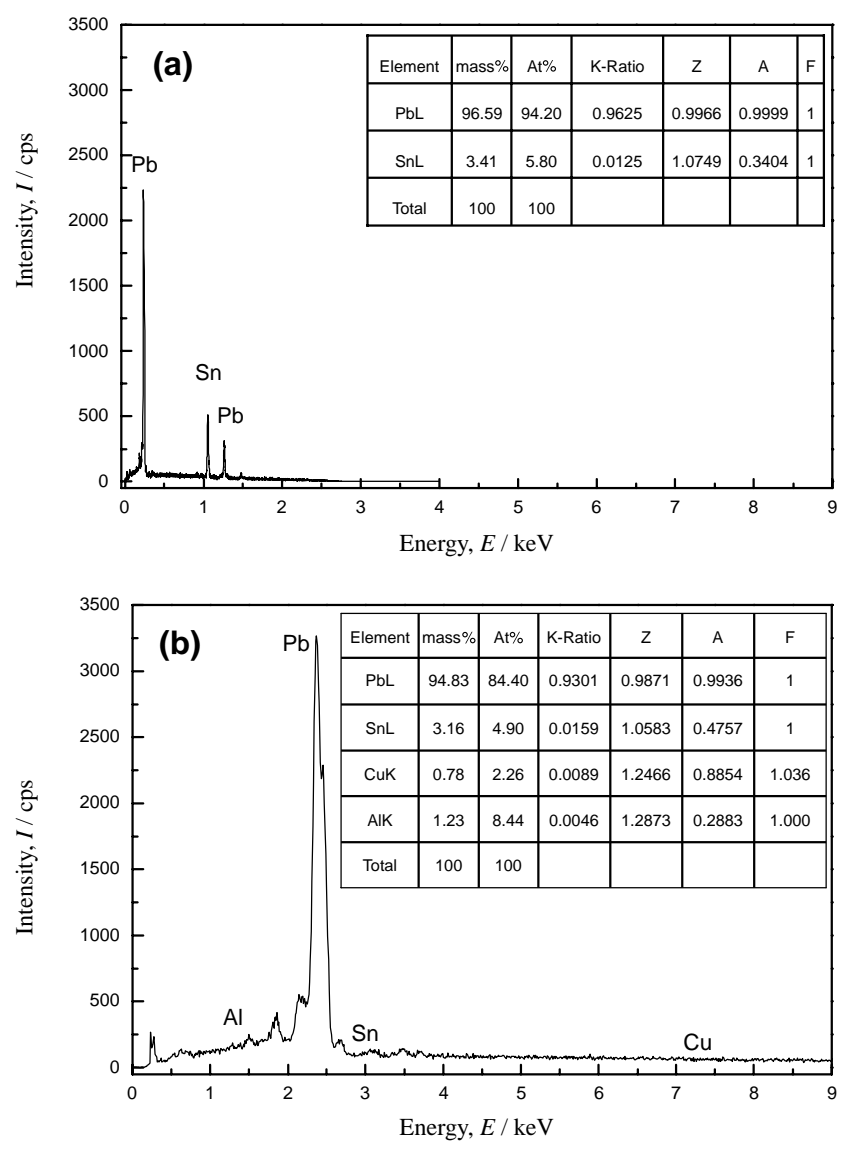

Fig. 4 Composition analysis of fracture surface. layer, before the aging and about $8.5 \mu \mathrm{m}$ thick IMC layer after the aging for 900 hours in $\mathrm{Sn}-37$ mass\% Pb solder. IMC layer grew quickly as the aging time increased. The growth rate of the $\mathrm{Sn}-97$ mass $\% \mathrm{~Pb}$ solder gradually decreased as the aging time increased, however, about $0.45 \mu \mathrm{m}$ thick IMC layer formed before the aging. A scallop-shape IMC of two kinds of solders grew in the interface. Figures 5(c) and (d) represent the results of EDS analysis of $\mathrm{Cu}_{6} \mathrm{Sn}_{5}$ and $\mathrm{Cu}_{3} \mathrm{Sn}$. Figure 6 shows the comparison of growth between the two kinds of solders as a function of the aging time. The thickness of the interfacial IMC layer was uneven, and therefore, the mean thickness of the IMC layer was calculated by dividing the value of the sectional area by the length of the base. In $\mathrm{Sn}-$ 97 mass $\% \mathrm{~Pb}$, IMC layer was thinner and its growth rate was slower than in $\mathrm{Sn}-37$ mass $\% \mathrm{~Pb}$. The $\mathrm{Sn} 3$ mass\%, the element of the solder, was too small amount to vigorously react with $\mathrm{Cu}$. As shown in figure, $\mathrm{Cu}-\mathrm{Sn}\left(\mathrm{Cu}_{6} \mathrm{Sn}_{5}+\mathrm{Cu}_{3} \mathrm{Sn}\right) \mathrm{IMC}$ grew in the shape of straight line until the aging below 900 hours. However, the thickness growth of the sample that had been aged for over 1500 hours was parabolic. Shaefer et al. reported that the growth of IMC layer is controlled by the diffusion. ${ }^{8)}$

Figure 7 represents the IMC that is formed at the interface between the solder and UBM. They are the additional processes need to join the $\mathrm{Sn}-37$ mass $\% \mathrm{~Pb}$ solder bump on the die pad to the bismaleimide triazine substrate, which is the underfill curing at the temperature of $438 \mathrm{~K}$ for 30 minutes and then one reflow soldering. The UBM with $\mathrm{Ti}(30000 \mathrm{~nm}) / \mathrm{Ti}-\mathrm{Ni}(25000 \mathrm{~nm}) / \mathrm{Ni}(200000 \mathrm{~nm})$ structure was formed, and compared with the $\mathrm{Cr} / \mathrm{Cr}-\mathrm{Cu} / \mathrm{Cu}$ structure. The scallop-shaped $\mathrm{Ni}_{3} \mathrm{Sn}_{4}$ layer of about $2.7 \mu \mathrm{m}$ thickness was formed. Compared with the thickness of the IMC layer at aging, IMC layer grew faster in a shorter time. The thickness of the Ni-Sn UBM was thiner than that of $\mathrm{Cu}-\mathrm{Sn}$ IMC because the diffusion coefficient of $\mathrm{Ni}$ is smaller than that of $\mathrm{Cu}$ in both of liquid-state and solid-state. Accordingly, the growth of the IMC depends more on the temperature of the reflow soldering condition than on that of the aging condition.

As the above results, the slow growth rate at the aging condition as compared the growth rate at the reflow soldering condition is caused by the solid-state diffusion. The aging is the diffusion process in solid-state while the soldering process is the fusion process. The growth rate in solid-state diffusion is slower than in the fusion process because the diffusion controlled the growth rate.

Figure 8 represents the TEM results at the nearby UBM in the $\mathrm{Sn}-37$ mass $\% \mathrm{~Pb}$ sample. The TEM bright image at the interface between $\mathrm{Ni}$ layer and $\mathrm{Ni}_{3} \mathrm{Sn}_{4}$ layer, and the diffraction patterns are shown in this figure. The diffraction patterns show the formation of the $\mathrm{Ni}_{3} \mathrm{Sn}_{4}$ layer in the Ni layer. Only the $\mathrm{Ni}_{3} \mathrm{Sn}_{4}$ layer was formed whereas $\mathrm{Ni}_{3} \mathrm{Sn}_{2}$ and $\mathrm{Ni}_{3} \mathrm{Sn}$ were not formed by the reciprocal action of the liquid solder and the solid metal during mounting the package on system board. Among the three kinds of compounds such as $\mathrm{Ni}_{3} \mathrm{Sn}_{4}$, $\mathrm{Ni}_{3} \mathrm{Sn}_{2}$ and $\mathrm{Ni}_{3} \mathrm{Sn}$, only $\mathrm{Ni}_{3} \mathrm{Sn}_{4}$ of the small forming energy of $38.5 \mathrm{~kJ} / \mathrm{g}$ atom was observed while $\mathrm{Ni}_{3} \mathrm{Sn}_{2}$ with the highest forming energy of $42.7 \mathrm{~kJ} / \mathrm{g}$ atom was not observed. The intermediate phases of $\mathrm{Ni}-\mathrm{Sn}$ in the joint area of the solder and UBM is believed to be caused by the effect of the interfacial energy generated between growing nucleus and the 

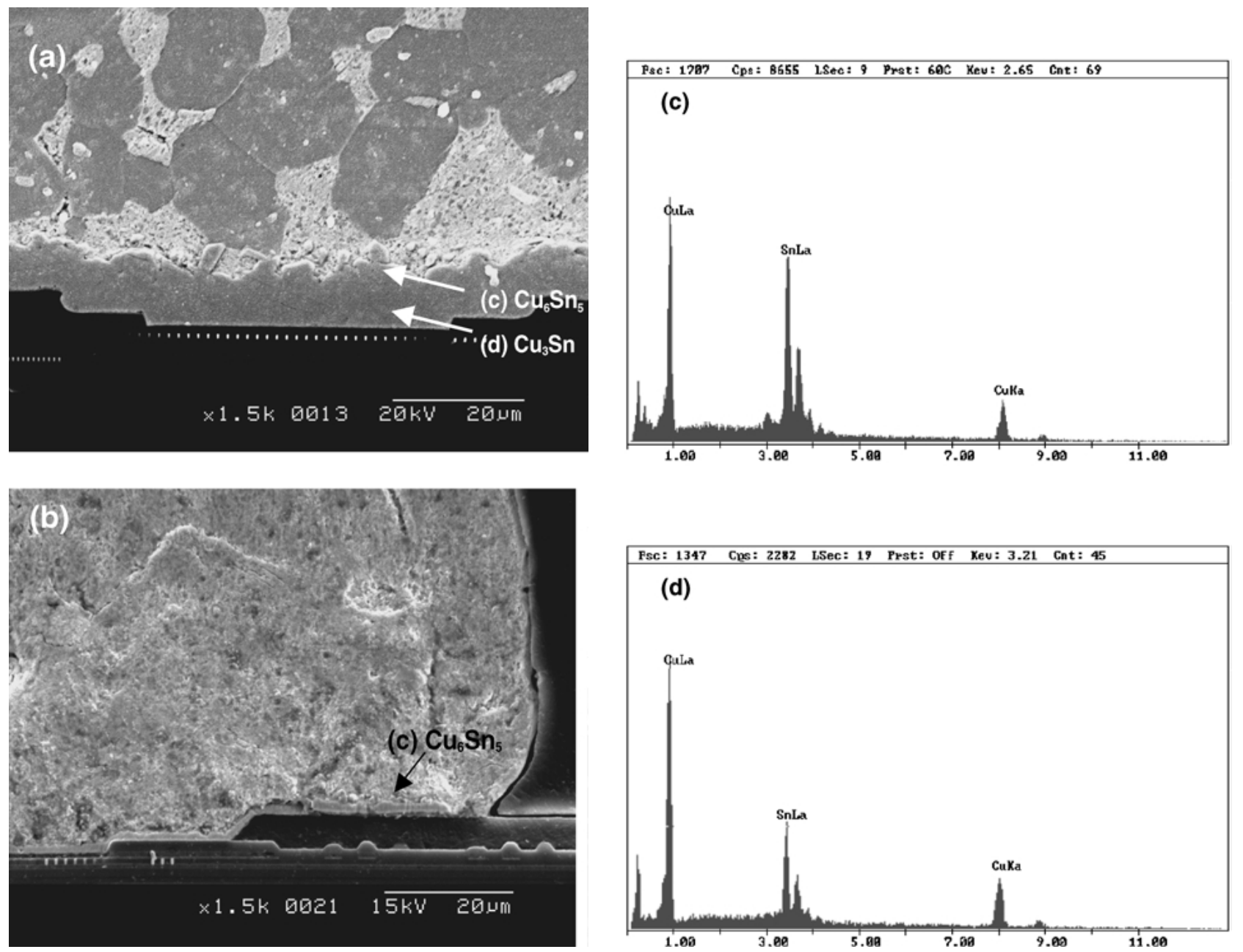

Fig. 5 IMCs at the interface between the UBM and a solder after aging at $448 \mathrm{~K}$ for $900 \mathrm{~h}$; (a) $\mathrm{Sn}-37 \mathrm{mass} \% \mathrm{~Pb}$ (b) $\mathrm{Sn}-97 \mathrm{mass} \% \mathrm{~Pb}$ (c) $\mathrm{Cu}_{6} \mathrm{Sn}_{5}$ (d) $\mathrm{Cu}_{3} \mathrm{Sn}$.

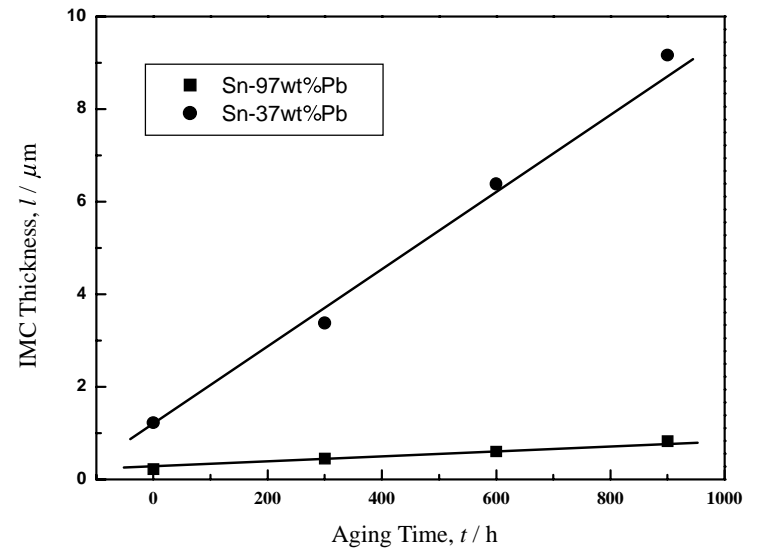

Fig. 6 The relation between IMC thickness and aging time for two $\mathrm{Sn}-\mathrm{Pb}$ Alloys.

matrix as well as the thermodynamic driving force. Generally, the activation energy barrier needed to grow the nucleus diminishes as the driving force increases and the interfacial energy between the nucleus and the matrix phase decreases. In addition, Fig. 8(a) shows the dark area on the upper side of the IMC. This area is believed to be caused by the sample preparation that uses the FIB. The projecting shape is due to an excess grind.

To predict the strain and the concentration of the stress,

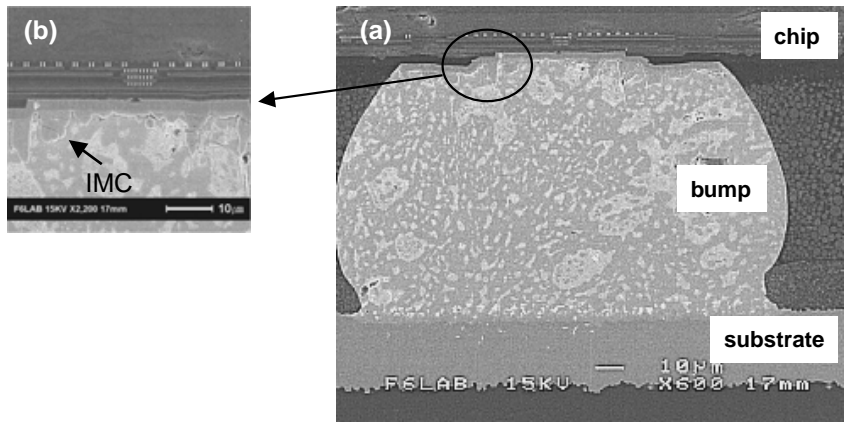

Fig. 7 Cross-sectional views of solder joint in FC-BGA; (a) solder joint (b) IMC layer.

FEA was carried out, and the results are shown in Fig. 9. The maximum stress concentration was calculated at the joint between the solder bump and UBM, where the initial fracture occurred. However, the stress distribution was broad inside the solder bump. This broadness means that the fracture occurs inside the solder. These results agree well with the results of the shear strength experiment, in which aging was carried out for less than 600 hours.

\section{Conclusion}

$\mathrm{Sn}-97$ mass $\% \mathrm{~Pb}$ and $\mathrm{Sn}-37$ mass $\% \mathrm{~Pb}$ solder bumps were prepared on the surface of $32 \mathrm{M}$ SRAM die pad. The shear 
(a)

\section{$500 \mathrm{~nm}$}
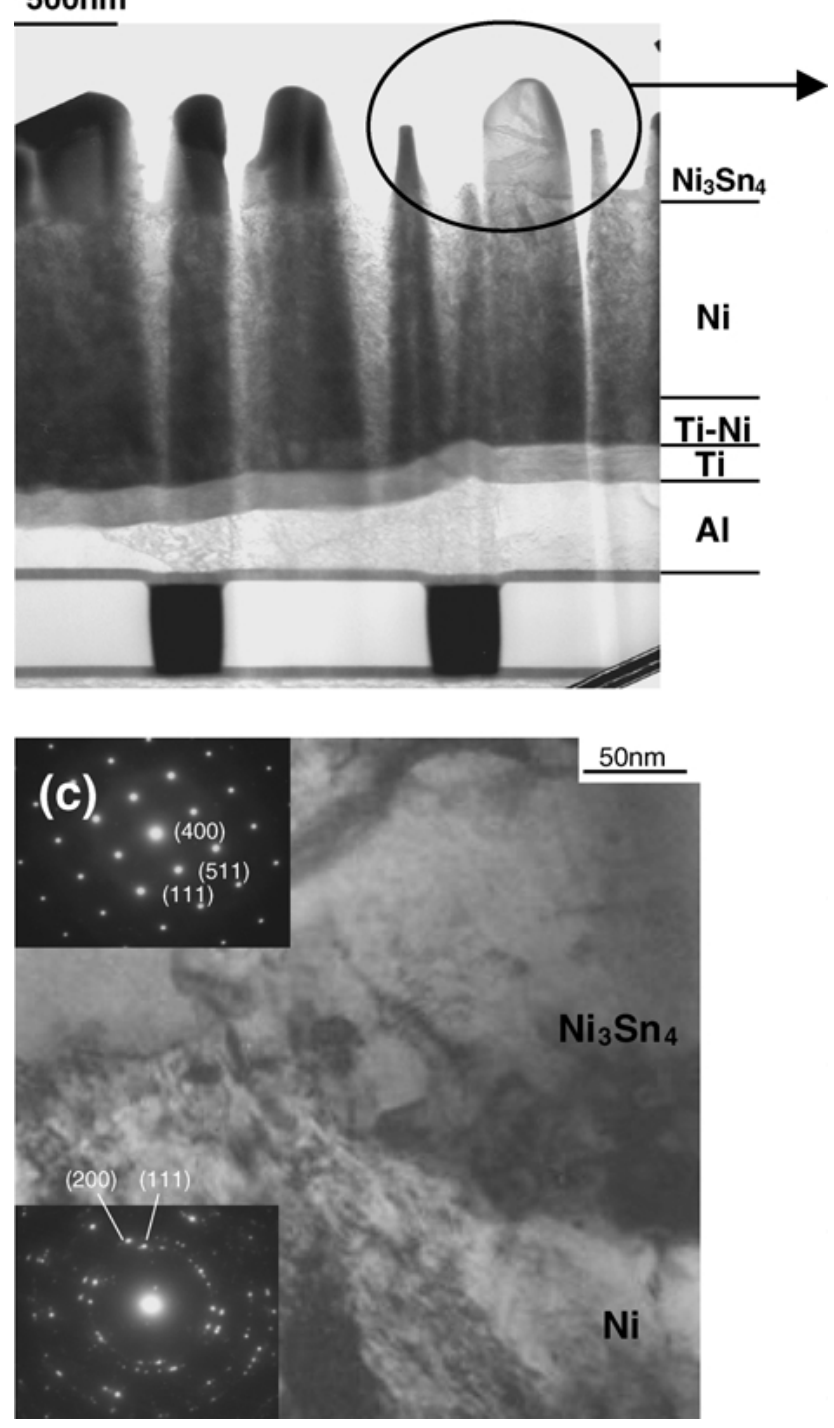

Fig. 8 TEM images of UBM-solder interface after FC-BGA packaging; (a) UBM and IMC (b) magnification photograph (c) diffraction patterns.

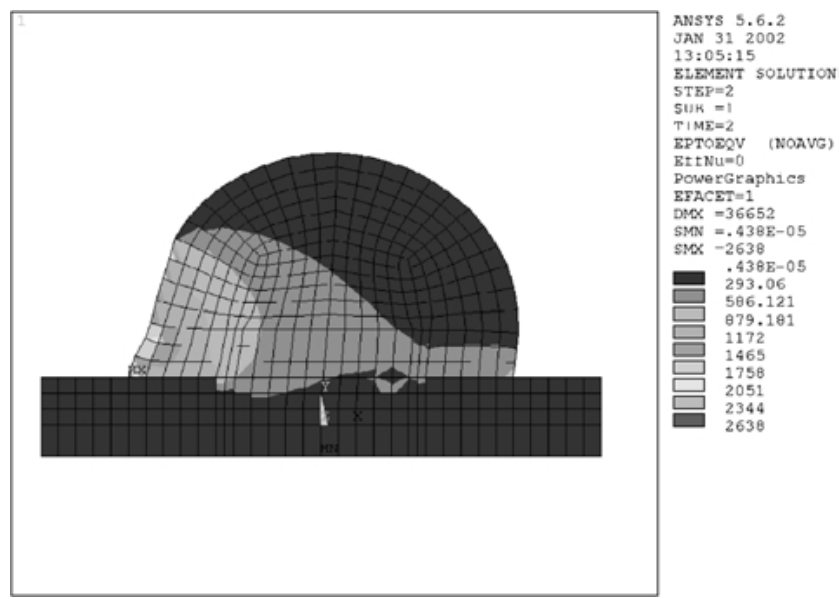

Fig. 9 Bump deformation shape and stress distribution of solder bump by finite element analysis. (b)

\section{0nm}

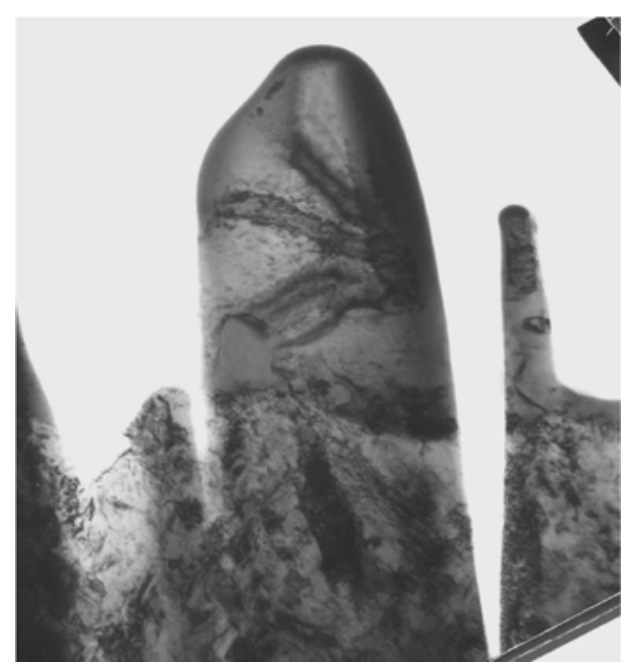

strength and fractured shape were analyzed according to aging treatment, and reliability between the solder and UBM was measured. The changes of the IMC growth were also evaluated. The conclusions of this study are summarized as followings.

(1) As the aging time increased, the shear strength of the two kinds of the solders decreased. Shear strengths of the $\mathrm{Sn}-97 \mathrm{mass} \% \mathrm{~Pb}$ and $\mathrm{Sn}-37$ mass\% $\mathrm{Pb}$ that were aged for 900 hours decreased by $25 \%$ and $20 \%$, respectively.

(2) The sample that was aged up to 600 hours fractured not at the multi-layer of UBM but inside the solder nearby the interfacial reaction layer. The faction at this location means that the joint between the UBM and the solder was firm. However, the fracture area in the sample after the aging over 900 hours moved from the inside of the solder to the interface of IMC layer.

(3) The IMC that was formed in the interface between $\mathrm{Sn}-37$ mass $\% \mathrm{~Pb}$ solder and $\mathrm{Cr} / \mathrm{Cr}-\mathrm{Cu} / \mathrm{Cu}$ layer was only $\mathrm{Cu}_{6} \mathrm{Sn}_{5}$ in the initial stage. On the other hand, the $\mathrm{Cu}_{3} \mathrm{Sn}$ as well as $\mathrm{Cu}_{6} \mathrm{Sn}_{5}$ was formed after aging at high temperature for a long time. The compound that is formed interface of $\mathrm{Ti} / \mathrm{Ti}-\mathrm{Ni} / \mathrm{Ni}$ is $\mathrm{Ni}_{3} \mathrm{Sn}_{4}$.

(4) The result of FEA showed that the stress was concentrated at the same area where the initial fractured had been observed.

\section{REFERENCES}

1) R. R. Tummala: Fundamentals of Microsystems Packaging, (McGrawHill, New York, 2001) pp. 361-367.

2) E. K. Young and I. Turlink: IEEE Trans. Comp. Hybrids, Manufact. Technol., 14 (1991) 549-559.

3) P. Su and S. Rzepka: J. Electron. Mater. 28 (1999) 1017-1022.

4) K. N. Tu: Acta Metal. 21 (1973) 347-350.

5) W. J. Tomlinson and N. J. Bryan: J. Mater. Sci. 21 (1986) 103-107.

6) P. T. Vianco, P. F. Hlava and A. C. Kilgo: J. Electron. Mater. 23 (1994) 583-594.

7) A. C. K. So: IEEE Trans. Comp. Packag. Manufact. Technol. Part B 20 (1997) 161-166.

8) M. Schaefer, R. A. Fournelle and Jin Liang: J. Electron. Mater. 27 (1998) 1167-1176. 